\title{
EMPRESARIOS, INNOVACIÓN Y ESTADO EN JOHN K. GALBRAITH Y MARIANA MAZZUCATO*
}

Antonio Nogueira Centenera

* DOI: https://doi.org/10.18601/01245996.v22n42.05 Recepción: 31-082018, modificación final: 15-08-2019, aceptación: 11-10-2019. Sugerencia de citación: Nogueira, C. A. (2020). Empresarios, innovación y Estado en John K. Galbraith y Mariana Mazzucato. Revista de Economia Institucional, 22(42), 109-125.

a Doctor en Economía. Docente investigador, Universidad Rey Juan Carlos, Madrid, España, [antonio.nogueira@urjc.es], [https://orcid.org/00000002-8802-8299]. 


\section{Empresarios, innovación y Estado en John K. Galbraith y Mariana Mazzucato}

Resumen. John K. Galbraith distinguió entre el sistema planificador dirigido por la gran empresa y el sistema de mercado de los empresarios. El cambio tecnológico y las alteraciones de la vida económica en los países industrializados han hecho inevitable el protagonismo de las grandes corporaciones en conveniencia con el Estado. No obstante, la empresa individual mantuvo relevancia en la obra de Galbraith: las artes y el diseño en sus múltiples facetas siguen siendo el baluarte de la empresa pequeña y una parte expansiva de la vida económica; y casi todo el mundo admira al empresario y no a las multinacionales. Hoy, el debate se ha trasladado al papel innovador del Estado, que percibe riesgos, opera atrevidamente al modo de los emprendedores y cataliza la inversión privada hacia nuevos sectores; como Mariana Mazzucato destaca en su obra.

Palabras clave: John Kenneth Galbraith, Mariana Mazzucato, empresas capitalistas, emprendimiento, tamaño de la firma; JEL: B31, P12, M13, L25.

\section{Entrepreneurs, innovation and State in John Kenneth Galbraith and Mariana Mazzucato}

Abstract. John K. Galbraith distinguished between the planning system directed by the large company, and the market system of entrepreneurs. Technological change and alterations in economic life in industrialized countries have made the role of large corporations in collusion with the State inevitable. However, the individual company maintained relevance in Galbraith's work: arts and design in many facets are the stronghold of small business, and an expansive part of economic life. Almost everyone admires the entrepreneurs, not the multinationals. Today, the debate has moved to the innovative role of the State that visualizes risks and operates daringly in the way of entrepreneurs, catalyzing private investment into new sectors -as Mariana Mazzucato highlights in her work.

Keywords: John Kenneth Galbraith, Mariana Mazzucato, capitalist enterprises, entrepreneurship, firm size; JEL: B31, P12, M13, L25

\section{Empreendedores, inovação e Estado em John K. Galbraith e Mariana Mazzucato}

Resumo. John K. Galbraith distinguiu entre o sistema de planejamento executado pelas grandes empresas e o sistema de mercado dos empreendedores. A mudança tecnológica e as alterações da vida econômica nos países industrializados tornaram inevitável o protagonismo das grandes corporações por conveniência com o Estado. No entanto, a empresa individual manteve relevância no trabalho de Galbraith: as artes e o design, em suas muitas facetas, continuam sendo o baluarte das pequenas empresas e uma parte expansiva da vida econômica; e quase todo mundo admira o empresário e não as multinacionais. Hoje, o debate passou para o papel inovador do Estado, que percebe riscos, opera com ousadia na maneira de empreendedores e catalisa o investimento privado em novos setores; como Mariana Mazzucato se destaca em seu trabalho.

Palavras-chave: John Kenneth Galbraith, Mariana Mazzucato, empresas capitalistas, empreendedorismo, tamanho da empresa; JEL: B31, P12, M13, L25 
I $\mathrm{n}$ los últimos tiempos, el proceso de diseño, lanzamiento y gestión Ede nuevos negocios se ha destacado como un modelo de creación de actividad, conocimiento y empleo. No obstante, se ha cerrado un gran número de nuevas empresas debido a la pérdida de financiación, la falta de demanda, las malas decisiones y la crisis económica. La historia del pensamiento económico puede iluminar a este respecto. John Kenneth Galbraith (1908-2006) alertó sobre los graves riesgos de la actividad empresarial ocasionados por el cambio tecnológico. Señaló que, en la sociedad industrial moderna, la forma característica de organización no es la pequeña empresa sino la gran corporación, una institución que poco se comprende.

Semana tras semana, mes tras mes, año tras año, ejerce en nuestra vida y en nuestro modo de vivir más influencia que los sindicatos, las universidades, los políticos y el gobierno. Existe un mito corporativo, cuidadosa y asiduamente divulgado. $\mathrm{Y}$ existe una realidad. Ambas cosas guardan poco parecido. La corporación moderna vive en suspensión entre la ficción y la realidad (Galbraith, 1981, p. 223).

Galbraith dedicó su prolífica vida a confirmar esta aseveración.

Hoy, con la idea de que los gobiernos fomenten el 'espíritu empresarial' mediante políticas que resuelvan el desempleo y promuevan el dinamismo social, se proponen medidas paternalistas como la creación de incubadoras de empresas y las técnicas de coaching, muy alejadas de la realidad. Según una reciente línea de pensamiento, el emprendedor efectivo no se encuentra en los negocios convencionales sino en el Estado, porque el esfuerzo tecnológico en $\mathrm{I}+\mathrm{D}+\mathrm{i}$ lo ha hecho inevitable. Mariana Mazzucato, galardonada con el Premio Leontief en 2018, sostiene en El Estado emprendedor y El valor de las cosas que algunos actores, retratándose como emprendedores, no crean valor sino que solo mueven el valor existente o incluso lo destruyen.

Con las lógicas diferencias de espacio y tiempo, ambos economistas aluden a un mito que dificulta el debate sobre el tamaño de la empresa y el papel de la innovación: el pequeño empresario aspira a alcanzar la escala de la gran firma (Galbraith) y la burocracia de la gran empresa añora las cualidades del emprendedor (Mazzucato). Este escrito destaca los aportes de ambos autores acerca de ese dilema inexistente, y muestra algunas sus semejanzas y diferencias con respecto a la conexión entre empresarios, innovación y Estado. 


\section{GALBRAITH: EL EMPRESARIODESPUÉS DE LA PLANIFICACIÓN TECNOLÓGICA}

El economista keynesiano e institucionalista nacido en Canadá quiso que El nuevo Estado industrial fuese su gran obra teórica. Se ha dicho de ella que "fue más allá de la crítica de la economía ortodoxa, más allá de Marx y Keynes, hacia una alternativa completa, hacia una completa sustitución del pensamiento neoclásico” (Galbraith James, 2007). En ese libro, la planificación en las grandes firmas implica "no solo coordinación, al igual que Coase; sino también que la empresa se prepara y atiende los hechos imprevistos" (Dunn y Pressman, 2005, p. 173).

Afín al New Deal de Franklin Roosevelt, en la Segunda Guerra Mundial, Galbraith fue director de la Oficina de Control de Precios (1941-1943), donde se formó una opinión insatisfactoria de los grandes empresarios que se incorporaban al esfuerzo bélico. Más tarde, hasta 1948 y antes de retornar a Harvard, como editor de Fortune -la principal revista de negocios de la época- se inmunizó “contra la mitología de los manuales de economía neoclásica, y su imagen de un mundo de empresas competitivas, en las cuales la autoridad y la propiedad coinciden en una sola persona y la guía corresponde a un solo cerebro" (Galbraith, 1981, p. 304).

Desde El capitalismo americano, donde expuso su teoría del "poder compensador", hasta La economía del fraude inocente, su testamento intelectual, dejó constancia de su preocupación por la gran empresa. En La sociedad opulenta - la primera de sus obras más conocidas- se refirió a un gran mito corporativo:

Precisamente debido a que vive una vida ordenada y metódica, el directivo se ve arrastrado a identificarse con el osado empresario de la literatura económica. En gran parte por la misma razón, el comandante de una división acorazada, que viaja en un remolque y que se tiene que ocupar de los suministros de gasolina, se considera a sí mismo al frente de una carga de la antigua caballería. El objetivo principal de una General Motors o una General Electric no ha sido otro que el de restringir y eliminar los peligros a los que se suponía estaba sujeto el antiguo empresario (Galbraith, 1960, p. 109).

La tesis de El nuevo Estado industrial es conocida. Robert Solow, entonces profesor del MIT, fue uno de sus primeros críticos. Pese a reconvenir a Galbraith por no dedicarse a ser un "pequeño pensador de lo específico”(Solow, 1967, p. 100), sintetizó como sigue los puntos esenciales de la obra:

- La forma característica de organización en la sociedad industrial moderna no es la pequeña empresa, sino la corporación gigante. 
- La gran empresa no es dirigida por sus propietarios, los accionistas comunes, sino por una burocracia organizada en una serie de comités superpuestos e interrelacionados.

- En la gran corporación altamente capitalizada y burocratizada existe la necesidad diaria de evitar cualquier tipo de riesgos.

- En vez de la "maximización de beneficios" clásica, la gran empresa persigue su propia supervivencia e independencia, centrándose en el crecimiento continuo de las ventas, la predicción de las ganancias, el virtuosismo tecnológico y el aislamiento ante toda interferencia adversa del gobierno.

- En el Estado industrial moderno, el recurso clave es la inteligencia científica, aplicada a la gestión corporativa.

Según Galbraith, la economía industrial moderna es de tipo bimodal: millones de pequeñas empresas conviven -cuando escribió dicho libro- con la mitad de la economía privada, dominada entonces por unas mil compañías que controlaban la mitad de las manufacturas y casi todos los servicios relevantes (bancos, telefonía, electricidad, ferrocarriles, líneas aéreas, seguros, grandes almacenes, cadenas de alimentación). Con estadísticas en la mano, Galbraith insistió en que lo que sucedía en Estados Unidos sucedía también en las demás naciones industrializadas:

Lo que determina la forma de la sociedad económica es el conjunto de los imperativos de la tecnología y de la organización, no las imágenes ideológicas. Este hecho es de agradecer, aunque seguramente no será bien recibido por aquellos cuyo capital intelectual y cuyo fervor moral están invertidos en la corriente de la economía de mercado como antítesis de la planificación social. Tampoco gustará a sus discípulos, los cuales, con inversiones intelectuales menos importantes, llevan las oriflamas del mercado libre y de la libre empresa $-\mathrm{y}$, por tanto y por definición, de las naciones libres- a la batalla política, militar o diplomática. Tampoco encantará a los que identifican de modo exclusivo planificación y socialismo. Desgraciadamente, no son éstas las ideas que gozan hoy de consenso público (Galbraith, 1967, p. 23).

En consecuencia, la era del pequeño empresario ha llegado a su fin en las sociedades desarrolladas, aunque sus más románticos defensores denuncien a los monopolios como causantes de la debacle, y no al condicionamiento tecnológico. "El enemigo del mercado no es la ideología, sino el ingeniero” (ibíd., p. 51). ¿Y dónde reside el nuevo poder? Galbraith reconoció que -en contra de la gran organización industrial y mercantil- el empresario particular sigue siendo el héroe del economista. Pero el poder ha pasado del individuo a la corporación, a lo que llamó la tecnoestructura: "la inteligencia que guía la empresa, 
el cerebro de la empresa" (ibíd., p. 91). La gran dimensión ¿es esencial para el logro de economías de escala?, ¿O se trata de monopolizar los mercados? Según él, ni una cosa ni la otra. Puso de ejemplo a la General Motors: su tamaño no está al servicio del monopolio ni de las economías de gran escala, sino al servicio de la planificación. "A pesar de ser lo suficientemente grande para disponer del poder de mercado que llamamos monopolio, los consumidores no protestan seriamente arguyendo que son explotados" (ibíd., p. 97).

¿Y de qué modo la tecnoestructura logra sus objetivos? Galbraith apunta a un conjunto de propósitos más generales de las grandes organizaciones. "La compensación pecuniaria no tiene por qué ser la motivación principal de los miembros de la tecnoestructura. También pueden ser fuerzas decisivas la identificación y la adaptación. Por encima de cierto nivel, esas fuerzas pueden obrar con independencia de la renta" (ibíd., p. 160).

La regulación de la demanda agregada, un sector público fuerte, la garantía, la subvención gubernamental de tecnologías avanzadas y una fuerza de trabajo calificada con otros elementos del nuevo Estado industrial. En tal contexto, ¿queda sitio para el empresario ajeno a la planificación?:

E1 empresario puede sobrevivir incluso a un grado importante de desarrollo industrial. Un empresario será probablemente tan capaz de dirigir una empresa minera grande como una pequeña. En los estadios primitivos y elementales de la industria del acero podía ejercer su poder con la misma planificación sobre $n$ hornos Bessemer que sobre uno solo. La única condición esencial es que la tecnología y la planificación se mantengan dentro de una relativa simplicidad, o con una extensión limitada (ibíd., p. 108).

No obstante, Galbraith advirtió una impostura crucial, que ya había señalado en La sociedad opulenta. "Los altos funcionarios de las compañías maduras gustaban de vestir en público el manto del empresario. Cultivaban una imagen de sí mismos en la que aparecían como hombres seguros e individualistas, con un toque de fundada arrogancia, de feroces competidores, y un deseo de vivir peligrosamente" (ibíd., pp. 112-113). Pero no hay que llamarse a engaño. "La afirmación del individualismo competitivo del ejecutivo de una gran compañía es, en la medida en que aún persiste, ceremonial y tradicional, o una manifestación de vanidad personal" (ibíd., p. 113).

Después de El nuevo Estado industrial y La sociedad opulenta, Galbraith completó su trilogía con La economia y el objetivo público. Eran tiempos del primer choque petrolero mundial. A diferencia 
de otros colegas de la izquierda académica, defendió el papel de las firmas multinacionales.

La tecnoestructura, al reproducirse en otros países, lleva su producto a otros países. Así comparte con los otros partícipes del mercado en el país extranjero los mismos conceptos sobre los precios, como lo hacía en su propia casa. [...] La General Motors, que opera a través de Opel de Alemania, se incorpora a la convención general oligopolística que prohíbe la competencia de precios en Alemania. Volkswagen y Mercedes-Benz, que venden en Estados Unidos, se someten de modo parecido al convenio que declara ilegal la destructora competencia de precios en Estados Unidos (Galbraith, 1975, p. 168).

Además, criticó las acusaciones de hegemonía dirigidas contra Estados Unidos.

E1 llamado desafío americano no es americano; es el desafío del sistema de planificación moderno. Si éste ha alcanzado su máximo desarrollo en Estados Unidos, ha sido debido a la extensión del país, a la carencia de una tradición feudal adversa, a su sistema legal, a su geografía, a sus recursos y a muchas otras circunstancias (Galbraith, 1975, p. 170).

En esta obra fue más allá de la tecnoestructura. Entre otros temas, abordó el futuro de los empresarios en el sistema de mercado. " $\mathrm{Nu}$ merosas empresas de servicios son productos derivados del auge de la gran empresa. Son, efectivamente, un fruto subsidiario del sistema de planificación, al cual apoyan" (ibíd.,p. 65). Un ejemplo de ello eran las franquicias, "por las cuales el individuo se hace responsable de una empresa local y, de este modo, se somete al sistema de incentivos inherente al empresario individual" (ibíd., p. 66). Observó nuevas oportunidades para el mercado, condicionadas por el sistema industrial:

Con el desarrollo económico y el consiguiente cambio social, el sector de servicios de la economía sobrevive y se expande, y esto es en gran parte un resultado del desarrollo del sistema de planificación y de la necesidad de administrar, facilitar y servir su consumo. Con ello, continuarán las oportunidades del pequeño empresario y de la pequeña empresa. Y, con el mismo ritmo, seguirá marcando esta parte del sistema de mercado (ibíd., p. 69).

Observa que si los servicios se resisten a la organización, también lo hacen las artes. A su entender la relación entre el sistema de mercado $\mathrm{y}$ las artes ha sido poco analizada.

E1 artista es, por naturaleza, un empresario independiente. Abarca una labor entera de creación; a diferencia del ingeniero o del científico productor de modelos, no aporta un conocimiento especializado de una parte de la tarea al trabajo de un equipo. Como se basta a sí mismo, no se somete de buen grado a los fines de una organización (ibíd., p. 70). 
Si las manufacturas requieren cierto grado de esfuerzo artístico y son juzgadas por ello, es frecuente que la superioridad artística de la pequeña empresa asegure su supervivencia frente a la gran organización. La gran empresa mantiene una producción continua, logra eficacia técnica y bajos costos y diseña buenas estrategias de mercado, a expensas de la estética o el buen gusto. En cambio, pese a su pequeñez, el empresario puede alcanzar la ventaja de un arte superior.

En la manufactura de vestidos, joyas, relojes, muebles y otros artículos domésticos, y en la cocina, la construcción y las ediciones, esta ventaja puede ser considerable [...]. Invariablemente, la pequeña empresa sirve al extremo más alto del mercado, es decir, sirve un producto más caro a los consumidores más opulentos, que tienen un gusto más refinado o (tal vez en la mayor parte de los casos) alguien más competente que les aconseja (ibíd., p. 72).

Reconoce que la respuesta del mercado a la innovación técnica suele ser más favorable que la respuesta a la innovación artística, y que la demanda de innovaciones técnicas aumenta a medida en que evolucionan las preferencias sociales. La ingeniería y la ciencia son socialmente necesarias, y el arte, por ende, es un lujo. Sin embargo, en los niveles más elevados hay una tendencia creciente al sentido artístico, que puede impulsar el progreso del empresario y preservar a la pequeña empresa.

Un apreciable volumen de actividad económica moderna depende, no de la eficiencia técnica del producto o de la eficacia con que es producido, sino de la calidad de los artistas que intervienen en su diseño. Algunas industrias basan en esto su fundamento [...] El renacimiento de la industria italiana de posguerra tiene una base parecida. Los productos italianos se distinguen sobre todo por su aspecto. Y existe una evolución parecida, aunque menos visible, en Estados Unidos. Es un hecho todavía poco reconocido, a nadie se le ocurriría poner al artista por delante del ingeniero, del científico o del director empresarial, como base del futuro desarrollo industrial. Pero el monopolio del logro artístico es importante garantía de supervivencia de la pequeña empresa (ibíd., p. 76).

Las artes y los productos que manifiestan la obra artística tendrán, pues, un papel central en el desarrollo económico durante mucho tiempo. Seguirán siendo un "baluarte importantísimo de la empresa pequeña y de la empresa individual” (ibíd., p. 78). Su expansión será mayor si se modifica la creencia social que asegura que las artes tienen menor derecho que la ciencia y la tecnología a los recursos públicos y privados.

Aunque al profesor de Harvard no se le oculta la sombra que se cierne sobre el empresario: la auto explotación. Mientras que en la 
gran compañía los empleados trabajan conforme a normas prescritas, aparte de la ley y la costumbre, nada regula la jornada de trabajo del empresario individual ni la intensidad de su esfuerzo. "Es, por decirlo con otras palabras, casi absolutamente libre de explotar su capacidad de trabajo, ya que es su propia capacidad, cosa que no ocurre en la organización" (ibíd., p. 81). La auto explotación -afirma- es sumamente importante para la supervivencia de la pequeña empresa en la agricultura, la venta al detal, los restaurantes, los servicios de reparación, los servicios domésticos y otros similares:

E1 empresario modesto, por carecer relativamente de fuerza en su mercado, no puede cargar el exceso de salarios o beneficios sobre el precio de venta al público. Piensa, acertadamente, que sobrevive gracias a que puede reducir el salario que percibe por su esfuerzo; y trata de ejercer el mismo derecho en lo que se refiere a sus empleados. De aquí su resistencia a los sindicatos, a la legislación de salarios mínimos y a todo cuanto puede aumentar el costo de la mano de obra (ibíd., p. 82).

Con todo, la gran corporación no es bien considerada por la sociedad, a deferencia del empresario. "El modesto hombre de negocios es el equivalente moderno de la pequeña empresa de la economía clásicamente competitiva”. Aunque tal admiración es el reflejo de la virtud social conveniente. "Se encomia lo que sirve a la comodidad y conveniencia de la comunidad”. Es cierto que al empresario, fuera de la organización, nadie le da órdenes, pero esa situación no es más que "cautela, sumisión, obediencia, incluso servilismo, del hombre cuya vida está a merced de sus parroquianos". El pequeño empresario es un bienhechor público y un modelo para los jóvenes, pero "nadie advierte que su fatigoso trabajo le es impuesto por las circunstancias del sistema de mercado" (ibíd., pp. 82-83).

Ante ese panorama, ¿la pequeña empresa está condenada a desaparecer? Hay tareas -agrícolas, servicios geográficamente dispersos, actividades artísticas- que no se prestan a la organización. El empresario no subsistirá donde hay organización, salvo si reduce su salario y aumenta su esfuerzo. Tal reducción y tal esfuerzo conducen a una evidente desigualdad entre los diferentes elementos que integran el sistema económico:

La virtud social conveniente confirma esta presunción al contribuir a que la gente se convenza de que debe aceptar una retribución inferior, de que una parte de su compensación reside en su virtud social. Es inútil decir que la presunción de desigualdad se fortalece mucho si una parte del sistema tiene poder sobre sus precios y costos, y estos son, a su vez, los costos y precios de la otra parte. Esto significa, naturalmente, que puede forzar la explotación de la otra parte (ibíd., p. 84). 


\section{MAZZUCATO: EL ESTADO INNOVADOR DESPUÉS DEL SILENCIO DE LAS GRANDES FIRMAS}

Si a comienzos del siglo XX solo se necesitaron 125 trabajadores y una inversión de 28 mil dólares para lanzar el primer Ford, cuando salió el Ford Mustang en 1964 se necesitaron 317 mil trabajadores y 6 mil millones de dólares. Como muestra del imperativo tecnológico, en El nuevo Estado industrial Galbraith puso el ejemplo del esfuerzo dedicado a ese flamante modelo: los costos del trabajo de ingeniería y de diseño rondaron unos nueve millones de dólares; el costo del equipo para producir el Mustang fue de cincuenta millones de dólares. El aumento del tiempo transcurrido entre el comienzo y la realización de la tarea, el aumento del capital comprometido en la producción, la necesidad de fuerza de trabajo especializada, además del tiempo y el capital arriesgado, exigieron una planificación eficiente.

En plena Guerra Fría, Galbraith sabía que la palabra 'planificación' tenía mala prensa entre sus compatriotas, pero consideraba que se trataba de una reacción mal encaminada. "La función de la planificación en la moderna sociedad industrial sigue siendo escasamente apreciada" (Galbraith, 1967, p. 39). La empresa invertía mayor cantidad de capital, y el esfuerzo de esa inversión no se podía abandonar al capricho de los consumidores. No obstante, reconoció que si bien la planificación era necesaria, eso no quería decir que siempre se realizara de manera adecuada. Aunque la resolución de problemas a través de la planificación "coloca elegantemente toda la discusión económica moderna bajo el título de investigación y desarrollo", desemboca en la carrera espacial y otros monumentales proyectos de la época.

Una respuesta a toda esta problemática consiste en hacer que el Estado absorba los riesgos mayores. E1 Estado puede suministrar o garantizar un mercado para el producto. Y puede garantizar los costos de desarrollo de un proyecto, de tal modo que si rebasan lo previsto la firma particular no tenga que soportarlos. $O$ puede pagar la investigación y suministrar el necesario conocimiento técnico. El sentido y la punta de todo esto son bastante evidentes. La tecnología lleva, en todas las circunstancias, a la planificación, y en sus manifestaciones más altas puede colocar los problemas de planificación fuera del alcance de las empresas industriales. Las necesidades de la tecnología y no la ideología ni la voluntad política impondrán a la firma el buscar la ayuda y la protección del Estado. Es una consecuencia de la tecnología avanzada, una consecuencia de interés no pequeño (ibíd., pp. 36-37).

Cinco décadas después, el arquetipo de la tecnología contemporánea no es el proyecto Apolo XIII que describió Galbraith, sino el iPhone de Apple. En El Estado emprendedor, Mariana Mazzucato, profesora 
en University College London, afirma que el espíritu emprendedor no tiene que ver únicamente con las start-ups, el capital de riesgo y los "inventores de garaje", pues "la mayoría de las innovaciones radicales y revolucionarias que han alimentado la dinámica del capitalismo -desde el ferrocarril hasta Internet y la nanotecnología y las farmacéuticas modernas- parten de inversiones iniciales 'emprendedoras' arriesgadas que se caracterizan por un uso intensivo de capital proporcionado por el Estado" (Mazzucato, 2014, p. 30). Y hace suya la conocida sentencia de Keynes en El final del laissez faire, el leitmotiv de su obra: "Lo importante para el gobierno no es hacer cosas que ya están haciendo los individuos, $y$ hacerlas un poco mejor o un poco peor, sino hacer aquellas que en la actualidad no se hacen en absoluto".

El Estado emprendedor deja de concebir el Estado como un Leviatán burocrático e inercial y pasa a considerarlo como catalizador de la inversión privada. La autora asegura que en el desarrollo de la aviación, la energía nuclear, los ordenadores, Internet, la biotecnología y la tecnología verde, "es y ha sido el Estado -y no el sector privadoel que ha arrancado y movido el motor del crecimiento, gracias a su disposición a asumir riesgos en áreas donde el sector privado ha sido demasiado adverso al riesgo" (ibíd., p. 46). No niega la existencia de actividad emprendedora en el sector privado, bien sea en las jóvenes nuevas empresas que dinamizan nuevos sectores (Google, p.ej.) o en la importante fuente de financiación privada en que consiste el capital de riesgo. Lo que Mazzucato impugna es la versión unilateral acerca del tema.

¿Cuánta gente sabe que una subvención pública de la Fundación Nacional para la Ciencia financió el algoritmo que llevó al éxito a Google, o que los anticuerpos antimoleculares, que sentaron las bases de la biotecnología antes de que el capital de riesgo entrara en el sector, se descubrieron en los laboratorios públicos del Consejo de la Investigación Médica (MRC) de Reino Unido? ¿Cuánta gente se da cuenta de que a muchas de las empresas jóvenes más innovadoras no las financió el capital de riesgo privado sino el público, como el que proporciona el Programa de Investigación para la Innovación en la Pequeña Empresa (SBIR)? (ibíd., pp. 57-58).

En su opinión, no se produce entonces un efecto crowding out sino un problema de free-riding: el Estado emprendedor invierte en áreas en las que el sector privado no invertiría aunque tuviese recursos. En cambio, la recompra de acciones por los directivos de las grandes firmas tecnológicas, que incrementan considerablemente las cotizaciones bursátiles, consolida el problema del polizón a bordo. "Aumentar el precio de las acciones no crea valor (que es el objetivo de la inno- 
vación), sino que facilita su extracción. Por tanto, a los accionistas y directivos los 'recompensamos' por montarse en la ola de la innovación que el Estado ha creado" (ibíd., p. 66).

Pese a que hay abundantes pruebas de que el Estado ejecuta adecuadamente políticas de $c a t c h-u p$ con objetivos específicos, orientando recursos hacia ciertos sectores industriales; la autora muestra que existen seis mitos que presionan al Estado para que se limite a financiar investigación básica y proporcione una infraestructura que beneficie al sector privado. Y pone en cuestión cada uno de esos mitos aportando las pruebas correspondientes:

- "La innovación consiste únicamente en I+D". La investigación de Mazzucato muestra que solamente las empresas farmacéuticas que han patentado durante cinco años seguidos, y que establecen alianzas, logran generar algún crecimiento a través de su gasto en $\mathrm{I}+\mathrm{D}$.

- "Lo pequeño es hermoso". Las pruebas más sólidas no destacan el papel de las empresas pequeñas sino el de las empresas jóvenes que crecen deprisa. Las subvenciones, los préstamos blandos o las exenciones fiscales a numerosas start-ups han llevado al despilfarro.

- "El capital de riesgo es amante del riesgo". La financiación del gobierno estadounidense (SBIR, ATP) a empresas tecnológicas en su estadio inicial supera entre dos y ocho veces la suma invertida por el capital de riesgo privado.

- "Vivimos en una economía del conocimiento: ; Basta con mirar cuantas patentes hay!". El aumento exponencial del número de patentes se ha logrado con grandes aportes de recursos públicos a la investigación, con herramientas de investigación básica (y no solo en productos y servicios finales) e incluso con "descubrimientos" tales como los genes.

- "El problema de Europa tiene que ver solo con la comercialización". No hay un NASDAQ europeo, es cierto, pero esa imitación ignora que el modelo excesivamente especulativo ha debilitado la innovación en Estados Unidos.

- "La inversión empresarial necesita 'menos impuestos y menos burocracia”. El avance de las fronteras del conocimiento no requiere subsidiar per se la I+D de las empresas individuales. Resulta más efectivo utilizar parte del gasto en desgravaciones fiscales a la $\mathrm{I}+\mathrm{D}$ para financiar directamente el avance tecnológico del cual se trate.

Mazzucato argumenta que el Estado asume la incertidumbre knightiana cuando invierte en el desarrollo de tecnologías en su fase temprana, bien sea en Internet, nanotecnología, energía nuclear o en la industria farmacéutica. Así nació el Estado emprendedor, que desde la Segunda Guerra Mundial hasta la actualidad -y con la creación 
de la Agencia de Proyectos de Investigación Avanzada en Defensa (DARPA) en 1958, que sentó las bases del boom de la industria informática en Silicon Valley-, hizo posible que Estados Unidos liderara la innovación en empresas grandes y pequeñas, en la universidad y en los laboratorios del gobierno. Mazzucato considera que ese es un país que pregona una retórica pro mercado que no coincide con la realidad. El “que está detrás del IPhone” es el Estado. De ahí que el mensaje de Steve Jobs ("Seguid hambrientos, seguid alocados") sea casi banal. Los éxitos de Apple gracias a sus ordenadores personales eran notables, pero con el lanzamiento del iPhone y del iPod Touch en 2007 sus ventas globales aumentaron un 460\%. Y, a lo largo de su trabajo, Mazzucato elabora una explicación convincente del origen y desarrollo de las tecnologías y los componentes incorporados en la primera generación de iPods, asociada directamente al esfuerzo del gobierno estadounidense para financiar y promover la investigación básica y aplicada. La clave del éxito de Apple es quizá distinta de la que se suele reconocer.

"Encontrar aquello que uno ama" y hacerlo siendo "alocado" es mucho más fácil en un país en el que el Estado tiene un papel decisivo en el desarrollo de tecnologías de alto riesgo, en la realización de las inversiones iniciales, elevadas y de alto riesgo, y en su sostenimiento hasta una etapa superior, en que aparecen los actores privados para "jugar y pasarlo bien" [...] Sin la inversión e intervención del gobierno de Estados Unidos, enfocadas en ciertos objetivos, es probable que la mayoría de los aspirantes a "Apple" hubieran terminado siendo perdedores en la carrera global para dominar la era de la informática y las comunicaciones. No hay que menospreciar el éxito organizativo de la empresa en integrar tecnologías complejas en dispositivos atractivos y fáciles de utilizar, junto a un poderoso software; sin embargo, no cabe duda de que la mayoría de las mejores tecnologías de Apple existen gracias a los esfuerzos colectivos y acumulativos promovidos por el Estado, que se hicieron en un entorno de incertidumbre y a menudo a favor, si no de la seguridad nacional, de la competitividad económica (ibíd., pp. 189-190).

Luego de examinar otros casos similares -como la "revolución industrial verde" y la energía eólica y solar-, la autora se muestra pesimista acerca del beneficio que obtiene el Estado por esas arriesgadas inversiones, porque dados los resquicios fiscales, los ingresos fiscales "no siempre reflejan en forma precisa el origen de las ganancias (p. ej., rentas del trabajo versus rentas del capital) [y] se ha demostrado cuán difícil es que el Estado obtenga los beneficios a cambio de sus inversiones a través de impuestos" (ibíd., p. 270). Volviendo a Apple, reconoce que Steve Jobs no aplicó políticas de corto plazo, "como la recompra de acciones o los programas de dividendos, que utilizan 
dinero que podría utilizarse en investigación y diseño", pero se ignora que tal innovación "ha dependido enormemente de elementos financiados por el Estado, y negarse a que el Estado sea recompensado no ayudará a que surjan nuevas Apples" (ibíd., pp. 287-288). E1 sempiterno problema de la socialización del riesgo y la privatización de las ganancias.

Más allá de la ideología del accionista, se pregunta Mazzucato: “¿Puede el Estado emprendedor comer también de su tarta?”. La profesora italo-estadounidense conoce la amplia literatura sobre la cambiante dinámica de las grandes empresas, las pequeñas empresas, la investigación gubernamental y los individuos en el proceso de innovación, pero señala que "todavía tenemos problemas para entender cómo se reparten los beneficios” (ibíd., p. 300). Tres cuartas partes de las entidades moleculares biofarmacéuticas recientes existen gracias a la labor de los laboratorios públicos. Las tecnologías que hacen "inteligente" al iPhone fueron financiadas por el Estado (Internet, las redes inalámbricas, el GPS, la microelectrónica, las pantallas táctiles, el asistente de voz Siri, etc.), pero aún no se han encontrado soluciones que propicien el crecimiento 'inteligente', inclusivo y sostenible que reclama la autora. Puesto que la historia de las nuevas tecnologías demuestra que la inversión privada tiende a esperar a que el Estado realice las riesgosas inversiones iniciales, Mazzucato argumenta que no basta hablar del 'Estado emprendedor', sino que se debe construir desde ahora, para que no se falseen los papeles:

Tal como sabe cualquier persona que haya trabajado en el sector privado, hay muchas empresas "burocráticas" e inerciales. No hay nada en el ADN del sector público que lo haga menos innovador que el sector privado. Pero, del mismo modo, fomentar la innovación y la creatividad en las instituciones del sector público requiere reflexionar sobre las dinámicas organizativas. Al negar la capacidad del sector privado para ser una fuerza innovadora desde dentro, la mayoría de expertos en gestión estratégica y cambio organizativo se han centrado más en el sector privado, dejando al sector público solo la función de "crear las condiciones" para que la innovación ocurra en el sector privado "revolucionario". Como he planteado antes, esto ha creado una profecía que se autocumple, en la que los jóvenes graduados más inteligentes opinan que es más interesante trabajar en Goldman Sachs o en Google que en un banco de inversión del Estado o en un ministerio de innovación. La única forma de reequilibrar este problema es mejorar el estatus del gobierno y las palabras e imágenes que utilizamos para describirlo, en vez de empeorarlos (ibíd., p. 317). 


\section{CONCLUSIONES}

John K. Galbraith no era un académico de pupitre. A diferencia de Keynes y Friedman, no propuso una doctrina que orientara la labor de generaciones enteras de economistas (Bradford DeLong, 2005). Sus conocimientos procedían de diversas fuentes, de su rica experiencia y de su relación con personas involucradas en la política, la economía y la problemática social. Su forma de razonar estaba asociada directamente con la acción. En su formación acumuló un gran acervo intelectual; y después expresó sus ideas con un estilo fluido y a veces mordaz. Su manera de trabajar y de expresarse quizá explique lo que otros llamaron lapsus académicos (Adams, 1984). El estudioso de la organización moderna fue un empresario intelectual que trabajó en solitario. "La falange académica que menospreció sus ideas estaba compuesta por hombres de organización, conformistas y celosos de sus privilegios académicos [...] Las herejías de Galbraith triunfaron en el mercado libre; en la universidad fueron reprimidas con los métodos que describió literalmente en su libro" (Galbraith James, 2008, p. 496).

A partir del análisis - de instituciones públicas y privadas- que realiza en El Estado emprendedor, en su última obra (El valor de las cosas), donde sistematiza su pensamiento, Mariana Mazzucato propone un debate "que ponga de nuevo el valor en el centro del razonamiento económico".

No se trata de establecer vallas firmes y estáticas alrededor del límite de producción y de sostener que algunos actores son parásitos o extractores, mientras que otros son gloriosos productores y creadores. Más bien, deberíamos tener una comprensión más dinámica de lo que significa crear y extraer en el contexto de la realidad social objetiva (Mazzucato, 2019, p. 379).

En la visión de Galbraith hay espacio para el pequeño empresario: un hecho poco apreciado por los comentaristas de su obra. E1 economista canadiense nacionalizado en Estados Unidos sostuvo que la perfección en el diseño y en el arte era la vía para el progreso de la pequeña empresa. La obra de Mazzucato no se ocupa de los negocios pequeños. No es su cometido. No cita a Galbraith, pero existe una continuidad en el pensamiento de ambos autores. No hay que forzar, pues, las diferencias.

Galbraith fue un pionero al constatar la relación simbiótica entre la corporación moderna y el Estado. Cinco décadas después, Mazzucato se pregunta "cómo transformar el ecosistema para que sea simbiótico 
en lugar de 'parasitario', para que la asociación público-privada incremente la apuesta, el compromiso y los beneficios de todos los jugadores que están invirtiendo en el juego de la innovación" (2014, p. 293). Galbraith argumentó que la planificación era poco apreciada porque "el sano instinto de los conservadores les sugiere que la planificación económica supone inevitablemente el control del comportamiento individual"(1967, p.39).Y Mazzucato argumenta que la participación del Estado en la empresa privada es temida "porque [se considera] que el paso siguiente es... el comunismo" (Mazzucato 2014, p. 309). Según el profesor de Harvard el enemigo del mercado es "la tecnología avanzada y la especialización de hombres y procesos requerida por esa tecnología, así como el compromiso resultante de tiempo y capital" (1967, p. 51). Para la profesora de UCL aún se habla, pese a las apariencias, de un capitalismo puro y duro: "las empresas capitalistas con más éxito tienen Estados activos que hacen inversiones arriesgadas, a los que se ha criticado con demasiada rapidez cuando las cosas han ido mal (p. ej., el Concorde) y se les ha recompensado muy poco cuando las cosas han ido bien (p. ej., en el caso de Internet)" (2014, p. 309).

En la década de 1950, Galbraith escribió un artículo ("La leyenda de Ford") donde cuestionó el genio técnico de Henry Ford. Fue la tecnoestructura de la Ford Motor Company la que hizo realidad el mito; cuando el viejo fundador despidió a los principales directivos, la compañía casi llega a la bancarrota. Mazzucato no niega el genio comercial y artístico de Jobs, el fundador de Apple, pero sí su talento científico. En suma, ambos observan una confusión y una usurpación de roles que dificulta el debate sobre el tamaño de la firma y la capacidad innovadora. La burocracia de la gran empresa con sus fines propios - la tecnoestructura - busca revestirse con la imagen (irreal) del emprendimiento; mientras que existen emprendedores que pretenden actuar y comportarse como una gran compañía, desconociendo sus limitaciones.

En síntesis, si el cambio técnico y organizativo altera la visión de la vida económica, como pensaba Galbraith, es claro que en los últimos lustros hemos pasado del nuevo Estado industrial al Estado emprendedor, como lo llama Mazzucato. Y puesto que quienes se oponen al Estado emprendedor no dejarán de formular sus prejuicios, sus partidarios deberían estar en guardia ante la vieja falacia que Galbraith solía recordar: "lo que no existe siempre sin excepción no existe nunca". 


\section{REFERENCIAS BIBLIOGRÁFICAS}

Adams, J. (1984). Galbraith on economic development. Journal of Postkeynesian Economics, 8(1), 91-102.

Bradford DeLong, J. (2005). Sisifus as social democrat. The life and legacy of John Kenneth Galbraith. Foreign Affairs, 84(3), 126-130.

Dunn, S. P. y Pressman, S. (2005). The economics contributions of John Kenneth Galbraith. Review of Political Economy, 17(2), 161-209.

Galbraith, J. K. (1960). La sociedad opulenta [1958]. Barcelona: Ariel.

Galbraith, J. K. (1967). El nuevo Estado industrial. Barcelona: Ariel.

Galbraith, J. K. (1972). El capitalismo americano [1952]. Barcelona: Ariel.

Galbraith, J. K. (1975). La economia y el objetivo público [1973]. Barcelona: Plaza y Janés.

Galbraith, J. K. (1981). La era de la incertidumbre [1977]. Barcelona: Círculo de Lectores.

Galbraith, J. K. (1982). Memorias. Una vida de nuestro tiempo [1981]. Barcelona: Grijalbo.

Galbraith, J. K. (2004). La economía del fraude inocente. Barcelona: Crítica.

Galbraith, James K. (2007). Foreword. The new industrial State (pp. xixxiii). Princeton: Princeton University Press.

Galbraith, James K. (2008). The abiding economics of John Kenneth Galbraith. Review of Political Economy, 20(4), 491-499.

Mazzucato, M. (2014). El Estado emprendedor [2013].Barcelona: RBA.

Mazzucato, M. (2019). El valor de las cosas [2018]. Barcelona: Taurus.

Solow, R. M. (1967). The new industrial State or Son of affluence. National Affaires, 100-108. 